\title{
Ductile and brittle behavior during deformation and fracture for pure ice detected by quasi-static indentation test
}

\author{
Yuki NAKAO*, Hiroyuki YAMADA**, Nagahisa OGASAWARA** and Takatoshi MATSUZAWA*** \\ ${ }^{*}$ Graduate School of Science and Engineering, National Defense Academy \\ 1-10-20, Hashirimizu, Yokosuka, Kanagawa 239-8686, Japan \\ E-mail: em57009@nda.ac.jp \\ **Department of Mechanical Engineering, National Defense Academy \\ 1-10-20, Hashirimizu, Yokosuka, Kanagawa 239-8686, Japan \\ ${ }^{* * *}$ National Maritime Research Institute \\ 6-38-1, Shinkawa, Mitaka, Tokyo 181-0004, Japan
}

Received: 3 March 2021; Revised: 16 April 2021; Accepted: 22 April 2021

\begin{abstract}
Ductile and brittle behavior during deformation and fracture for ice have attracted considerable research interest. The strength of ice has been reported to depend on the temperature, strain rate, and other factors. In addition, the tip shape of an object that comes into contact with ice is one of the important factors which influence the fracture phenomenon of ice. However, the associated fracture mechanisms have not been clarified. Therefore, in this study, a quasi-static indentation test was performed to investigate the deformation and fracture properties of pure ice. The displacement rate ranged from 0.002 to $2 \mathrm{~mm} / \mathrm{s}$, and the test temperature was approximately $-10^{\circ} \mathrm{C}$. Conical indenters with indenter angles (apex angles) of 90,120 , and $140^{\circ}$ and spherical indenters with diameters of 10,15 , and $20 \mathrm{~mm}$ were used. In the case of the conical indenters, the maximum load at effective strain rates of $10^{-1}$ and $10^{0} \mathrm{~s}^{-1}$ increased owing to the temporary stagnation of the cracks, caused by the negative rate dependence of the ice strength. In contrast, in the case of the spherical indenters, the maximum load at effective strain rates from $10^{-4}$ to $10^{-1} \mathrm{~s}^{-1}$ exhibited a trend similar to that in the uniaxial compression test: specifically, the maximum load peaked at $10^{-3} \mathrm{~s}^{-1}$ and then decreased with further increase in the strain rates. Furthermore, the contact radius when the ice fractured did not change considerably for different indenter shapes. This finding indicated that the internal deformation distribution caused by the indentation considerably influenced the deformation and fracture properties of ice. A larger indenter angle or diameter of the conical or spherical indenters, respectively, corresponded to a larger internal deformation distribution and a smaller displacement pertaining to the fracture.
\end{abstract}

Keywords : Ice, Fracture, Indentation, Quasi-static, Strain rate dependence

\section{Introduction}

Ice has been a subject of research in several science and engineering domains. In particular, ice is widely studied in the context of planetary science as it is a principal component of the objects in the solar system. To clarify the origins of planets and satellites, several researchers have examined the ice particles present in the low-temperature region of outer space and the upper atmosphere of the Earth (Smoluchowski, 1979; Ros and Johansen, 2013), and high-speed ice collision experiments (Kawakami et al., 1983; Arakawa et al., 2000) have been conducted. In addition, because ice is abundantly present on the Earth, the ice crystal growth (Peterson et al., 2010; Yokoyama et al., 2011) and surface melting phenomenon of ice (Wei et al., 2001; Murata et al., 2016) have been examined to elucidate the natural phenomena related to ice. Furthermore, the variations in glaciers and ice sheets (Clark et al., 1999; Yokoyama et al., 2018) have been observed to clarify the climate characteristics. In the engineering domain, the deformation and fracture properties of ice have been studied to formulate measures to reduce the damage from ice disasters and effectively utilize ice. Ice fracturing leads to several problems, such as damage to cars and buildings subjected to hail, collision of sea ice and ships, and 
detachment of ice blocks from aircraft. Ice is also used as a transportation route or runway in certain applications. In this regard, the rate dependence of the deformation and fracture properties of ice must be examined, as these phenomena occur at different rates for different applications.

The mechanical properties of ice are usually evaluated by conducting bending and compression tests. However, in this study, we will focus on uniaxial compression and tensile properties. Ice on earth is the material at the boundary of phase-change, and it can be regarded as a high-temperature material, i.e., ice undergoes creep deformation. Consequently, the theory of creep deformation, which has been developed for metallic materials, has been extended to ice (Glen, 1955; Barnes et al., 1971). Several researchers have reported that the strength of ice is governed by several parameters including the temperature (Higashi et al., 1964; Hawkes and Mellor, 1972), strain rate (Gold, 1977; Mellor and Cole, 1982), porosity (Schwartz and Weeks, 1977; Timco and Weeks, 2010), and grain size (Cole, 1987).

Ice exhibits either ductile or brittle behavior depending on the strain rate. The concept of deformation caused by dislocations has been considered in the ductile domain (Ahmad and Whitworth, 1988). It has been reported that the ductile-brittle transition region exists at strain rates from approximately $10^{-4}$ to $10^{-3} \mathrm{~s}^{-1}$ (Hawkes and Mellor, 1972; Schulson, 1997). During ductile fracture, the strength of ice increases with an increase in the strain rate; however, this trend changes above the transition point. Schulson (1990) indicated that the compressive strength of ice decreases with increasing strain rates when the strain rate range between $10^{-3}$ and $10^{-1} \mathrm{~s}^{-1}$. Cole (1987) considered the strain rate ranging from $10^{-7}$ to $10^{-1} \mathrm{~s}^{-1}$ and suggested that the strength became independent of the strain rate at strain rates ranging from $10^{-}$ ${ }^{2}$ to $10^{-1} \mathrm{~s}^{-1}$. It can be considered that the data variations are relatively large in the brittle domain. However, it is generally recognized that the ice strength increases until the strain rate increases to approximately $10^{-3} \mathrm{~s}^{-1}$ and then decreases or stagnates at approximately $10^{-3}$ to $10^{-1} \mathrm{~s}^{-1}$. Relatively few studies have been focused on the strength of ice at high strain rates, although certain recent studies (Kim and Keune, 2007; Wu and Prakash, 2015) indicated that the strength increased at the impact strain rate (from approximately $10^{2}$ to $10^{3} \mathrm{~s}^{-1}$ ). In general, the flow stress of metal and plastic materialsfor which the dependence of the strength on the strain rate has been investigated in detail-increases with the increasing strain rate (Hoge and Mukherjee, 1977; Tsuda et al., 2012). Ice exhibits a strain rate dependence that is unlike that of other materials under ambient temperatures, and this aspect was a key focus in the present study.

Sharp objects such as ice picks are widely used to fracture ice in everyday life. Moreover, ice easily fractures when impacted with the back of metallic spoons. It is likely that the tip shape of these objects influences the fracture phenomenon of ice. This aspect was another key focus in the present study, and it was examined by conducting an indentation test.

Uniaxial tests are widely conducted to evaluate the mechanical properties of a material. However, in such tests, the mechanical properties at the nano- or micrometer scales cannot be evaluated. Indentation testing overcomes this limitation, and it is therefore widely applied to realize the mechanical evaluation of metals, thin films and polymer materials. In particular, the indentation test is a hardness test to evaluate the elastic and plastic properties of engineering materials by continuously measuring the history of load and displacement when penetrating a homogeneous solid by using a rigid indenter (Fischer-Cripps, 2011). Indenters with various shapes, such as spherical, conical, Vickers (foursided pyramid), and Berkovich (three-sided pyramid) indenters can be used to conduct these tests (Fischer-Cripps, 2011).

Indentation testing has also been applied to study ice, albeit in a different context. A common research topic is the damage to offshore structures caused by ice collisions. In particular, when constructing offshore structures or ships, it is necessary to accurately evaluate the acting loads and pressures when a structure collides with ice. Because the natural sea ice has irregularities, high-pressure zones are locally generated when the ice contacts offshore structures. To reproduce this situation, primarily field testing is performed using plane indenters, although laboratory experiments using spherical indenters have been performed by Barrette et al. (2002), Mackey et al. (2007) and Wells et al. (2011). However, only one or two types of spherical indenters were used in these studies, and the effect of the indenter shape was not extensively considered. Furthermore, these studies focused on the localized high-pressure zones or the damaged ice layer that occurred owing to the interaction between the ice and offshore structure, instead of the internal crack propagation or ice fracturing. Although Michel and Toussaint (1977) performed indentation tests to measure the histories of the load and displacement by using a rectangular indenter and proposed an effective formula to estimate the strain rate in ice plates, this formula is limited to the indentation on a plane and cannot be applied to spherical or conical indenters. Ulan-Kvitberg et al. (2011) were conducting ice crushing tests using a conical and wedge shaped indenter, but the indenter angle did not changed.

This discussion indicates that the mechanical properties of ice represent a popular research topic from the viewpoint 
of mechanical science and engineering, and indentation testing is an effective method to evaluate the mechanical properties. However, little has been reported on the effect of the indenter shape on the ice fracturing through indentation testing. Moreover, the mechanism of ice fracturing, which is likely attributable to the shape of the indenter such as an ice pick or a metal spoon, has not been clarified. To address these aspects, in this study, the deformation and fracture properties of pure ice were examined by performing quasi-static indentation tests. In particular, the effect of the indenter shapes on these properties was investigated using three types of conical and spherical indenters, respectively. Furthermore, the results of the indentation test were compared with those of a uniaxial test to evaluate the effect of the loading state.

\section{Material and methods 2.1 Specimen}

In a laboratory setting, it is difficult to produce transparent ice without impurities. Thus, commercially available pure ice was used in this study to stabilize the test conditions. The pure ice block $(260 \mathrm{~mm} \times 550 \mathrm{~mm} \times 1000 \mathrm{~mm}) \mathrm{was}$ cut into 36 equal parts, and one of them was processed into a rectangular parallelepiped $(20 \mathrm{~mm} \times 20 \mathrm{~mm} \times 30 \mathrm{~mm}) \mathrm{by}$ using a band saw. Prior to surface finishing, this specimen was set on a mount. In terms of the mount, an aluminum alloy and acrylonitrile butadiene styrene resin, which exhibited a high and low thermal conductivity, were used for the ice contact part and the surrounding area, respectively. The surface in the height direction of the ice was slightly melted on a metal plate and fixed on the specimen mount. In this manner, the ice specimen could be fixed and a low temperature could be maintained by cooling the aluminum alloy plate by using dry ice. Subsequently, the specimen was placed on a microtome (REM-710; Yamato Kohki Industrial Co., Ltd), and the upper surface of the ice was cut in $10 \mu \mathrm{m}$ steps such that the height became $20 \mathrm{~mm}$. These $20 \mathrm{~mm}$ cubic specimens were used for the experiments.

To evaluate the shape of the crystal grains, a thin ice specimen (with a thickness of approximately $1 \mathrm{~mm}$ ) was placed between two polarizing plates and observed. Figures 1 (a) and (b) show the polarization photographs of a section perpendicular and parallel to the freezing direction of the ice crystal, respectively. The ice specimen was polycrystalline ice composed of several columnar ices. The grains were coarse, with a size ranging from approximately 5 to $10 \mathrm{~mm}$. The indentation test was performed in the plane parallel to the freezing direction of the crystal (Fig. 1 (b)) to unify the experimental conditions.

(a)

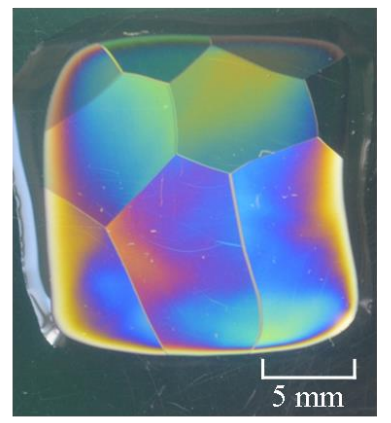

(b)

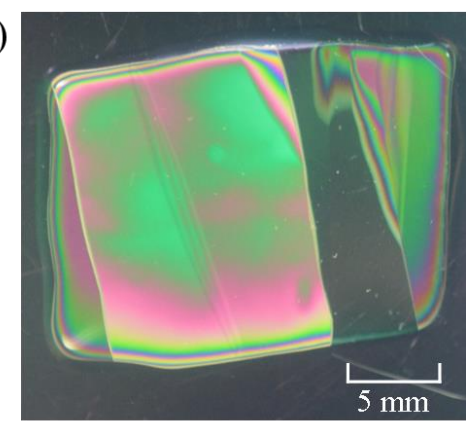

Fig. 1 Typical microstructure of ice specimen: sections (a) perpendicular and (b) parallel to the freezing direction.

\subsection{Quasi-static indentation test}

The tests were conducted using a universal material testing machine (5982; Instron) with a load cell capacity of 100 $\mathrm{kN}$ and a cooling chamber (CLC-01; Collet Industrial Co., Ltd.) connected to a forced convection cooling system (Fig. 2). Nitrogen gas flowed into the liquid nitrogen storage container from the nitrogen cylinder, and low-temperature nitrogen gas was fed to the chamber to cool the inside of the chamber. The temperature inside the chamber was measured using a K-type thermocouple and verified using a temperature control device (MC-1000R; Collet Industrial Co., Ltd.). The flow rate of the nitrogen fed to the chamber was manually adjusted using a nitrogen gas control device (MC-500; Collet Industrial Co., Ltd.) while checking the temperature. The test was performed at an ice temperature of $-10.1 \pm$ $0.3^{\circ} \mathrm{C}$, realized after maintaining the temperature in the chamber at $-10 \pm 1^{\circ} \mathrm{C}$ for $15 \mathrm{~min}$. 
Figure 3 shows the schematic of the inside of the chamber. A conical indenter with an indenter angle (apex angle) of 90,120 , or $140^{\circ}$, or a spherical indenter with a diameter of 10,15 , or $20 \mathrm{~mm}$ was attached to the tip of the upper jig. The tip shape of the conical indenter was observed using a laser microscope. It was noted that the tip was not completely sharp due to the processing accuracy, and it was frequently chipped. Therefore, the displacement and load were considered to be underestimated compared to those for a sharp tip in conical indentation tests. Although a previous report (Oliver, 1992) proposed an approach to correct the roundness of the indenter tip for metallic materials, this method could not be applied to the ice specimen as it would crack. The displacement $h$ obtained in the indentation test was corrected considering the missing length at the tip, $\Delta h$, as shown in Eq. (1), which yielded $h_{t}$ as the displacement.

$$
h_{t}=h+\Delta h
$$

Nevertheless, the initial load value was estimated to be smaller than the original as the load could not be corrected. The ice specimen was fixed to the jig at the bottom, together with the specimen mount. The displacement rates were set as $0.002,0.02,0.2$, and $2 \mathrm{~mm} / \mathrm{s}$. The indentation tests were performed 5 to 10 times under each condition to suppress variations in the results.

(a)

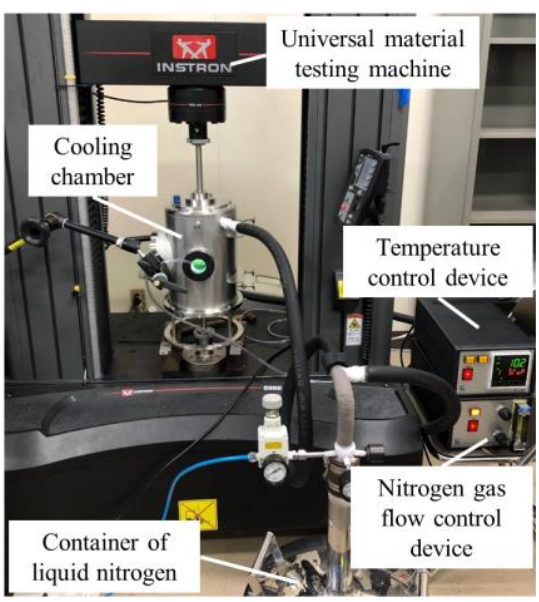

(b)

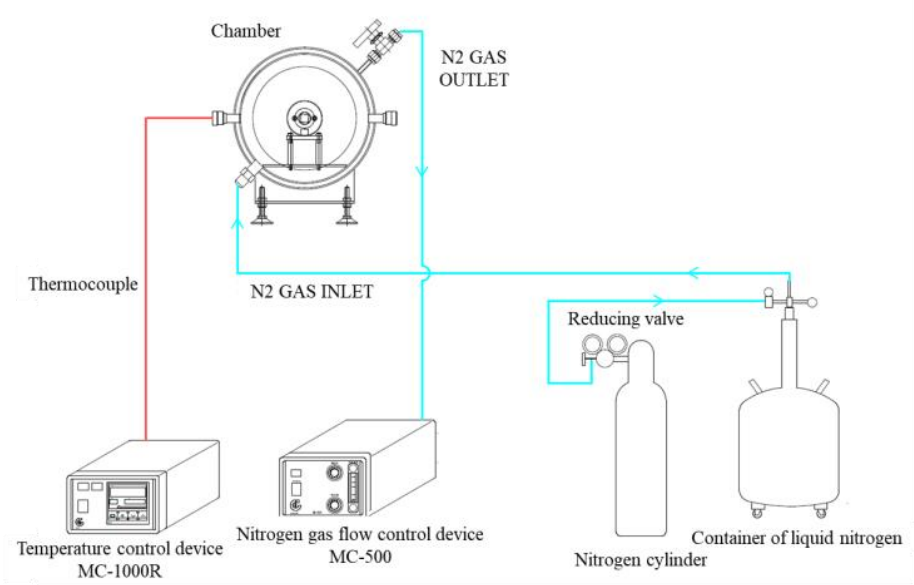

Fig. 2 (a) Photograph of the quasi-static indentation test equipment. (b) Schematic of the cooling system. The arrows indicate the direction of flow of nitrogen gas.

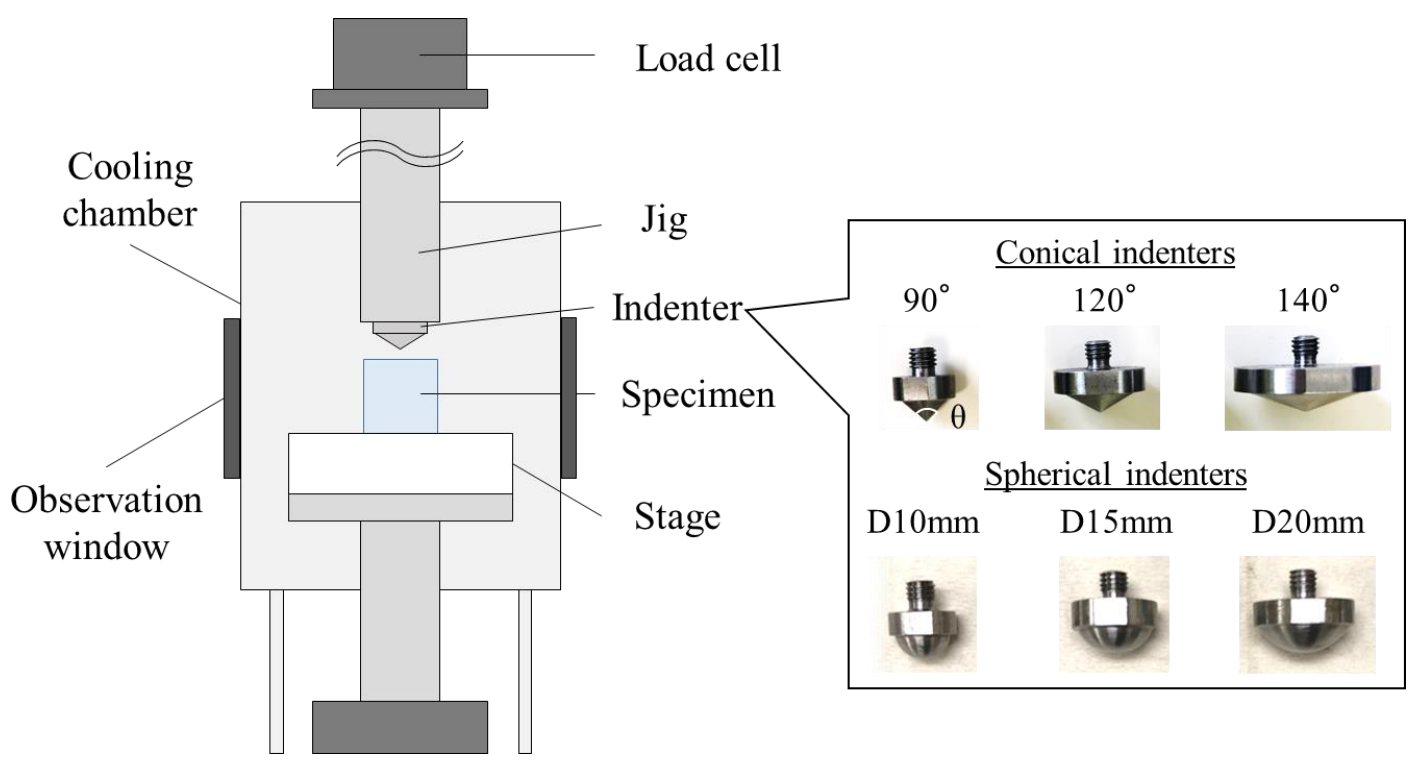

Fig. 3 Schematic of the inside of the cooling chamber and images of the conical and spherical indenters. 


\subsection{Observation of deformation and fracture}

The states of deformation and fracture of the ice specimen were recorded using a digital video camera (D5200; Nikon Co., Ltd.) and a high-speed camera (MEMRECAM HX-3; nac Image Technology Inc.) installed in front of the observation window of the chamber, with frame rates of 25 and $2000 \mathrm{fps}$, respectively. The digital video camera was used at displacement rates of $0.002,0.02$, and $0.2 \mathrm{~mm} / \mathrm{s}$, and the high-speed camera was used at the displacement rate of $2 \mathrm{~mm} / \mathrm{s}$. A metal halide lamp (POCKET PAR 125; ARRI) with an output of $125 \mathrm{~W}$ was used as the light source.

\section{Results}

\subsection{Load-displacement relationship}

Figures 4 and 5 show the typical load-displacement relationships at each displacement rate. In general, when an indentation test is performed on metallic materials, the load increases with an increase in the displacement. A similar trend was observed in the case of the ice specimens. We define the significant load drop in the load-displacement relationship as the fracture of ice. This is synonymous with the maximum load. When using the conical indenters, the load increased with barely any fluctuations during the indentation at the displacement rates of $0.002 \mathrm{and} 0.02 \mathrm{~mm} / \mathrm{s}$; however, the load slightly decreased during the indentation at higher displacement rates of 0.2 and $2 \mathrm{~mm} / \mathrm{s}$. In contrast, when using the spherical indenters, the load increased without decreasing until the maximum load was reached.

Figure 6 shows the relationship between the maximum load and displacement rate. The maximum load tended to increase as the indenter angle or sphere diameter increased. In the case of the conical indenters, the maximum load decreased as the displacement rate increased from 0.002 to $0.02 \mathrm{~mm} / \mathrm{s}$, increased while the displacement rate increased to $0.2 \mathrm{~mm} / \mathrm{s}$, and decreased again at the displacement rate of $2 \mathrm{~mm} / \mathrm{s}$. In contrast, in the case of the spherical indenters, the load peaked at the displacement rate of $0.02 \mathrm{~mm} / \mathrm{s}$ and then decreased as the displacement rate increased. Furthermore, with an increase in the diameter of the spherical indenter, the maximum load at the displacement rate of $0.02 \mathrm{~mm} / \mathrm{s}$ further increased.

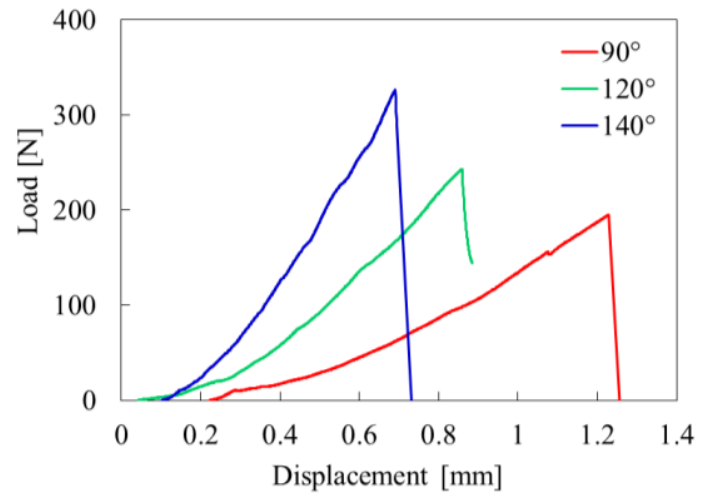

(a) $0.002 \mathrm{~mm} / \mathrm{s}$

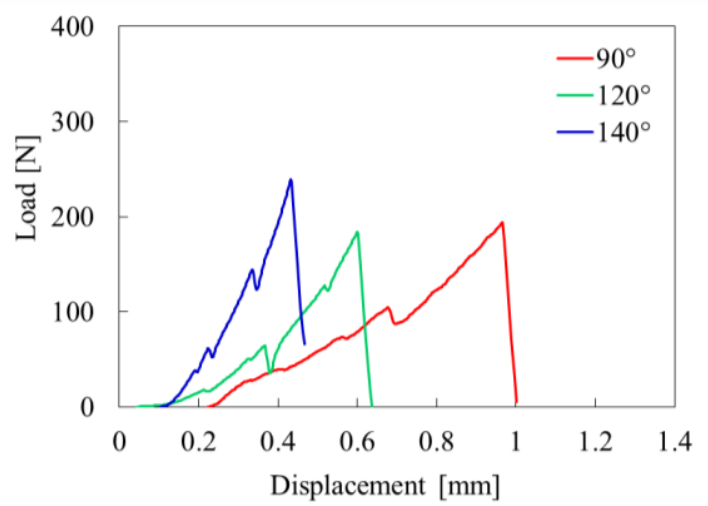

(c) $0.2 \mathrm{~mm} / \mathrm{s}$

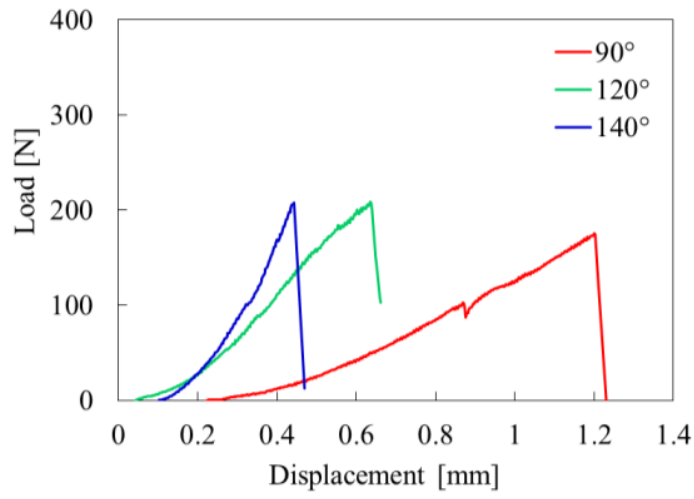

(b) $0.02 \mathrm{~mm} / \mathrm{s}$

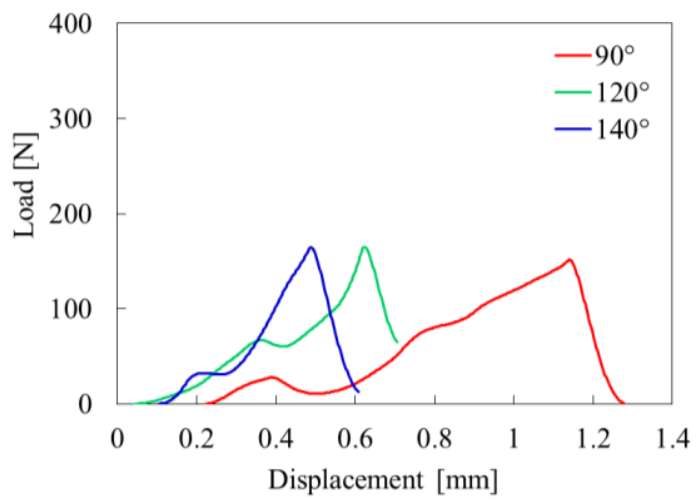

(d) $2 \mathrm{~mm} / \mathrm{s}$

Fig. 4 Relationships between typical load and displacement when using conical indenters with different apex angles. The displacement is shown as corrected value using Eq. (1). 


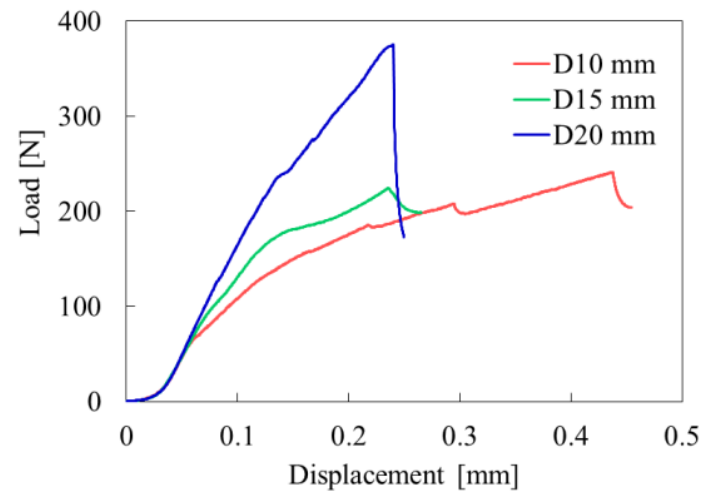

(a) $0.002 \mathrm{~mm} / \mathrm{s}$

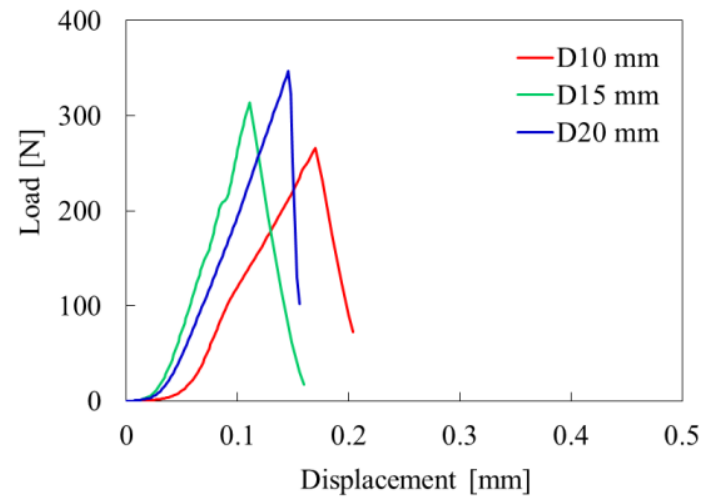

(c) $0.2 \mathrm{~mm} / \mathrm{s}$

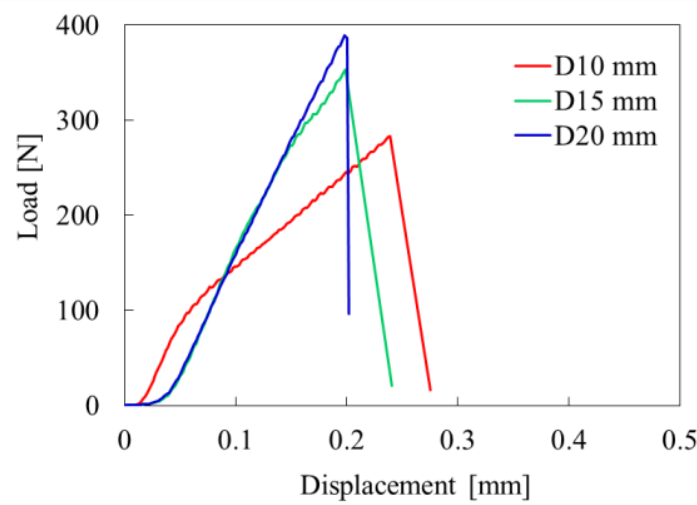

(b) $0.02 \mathrm{~mm} / \mathrm{s}$

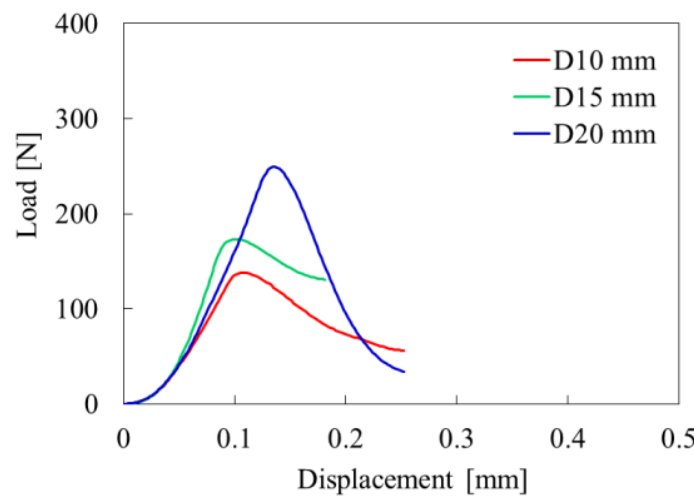

(d) $2 \mathrm{~mm} / \mathrm{s}$

Fig. 5 Relationships between typical load and displacement when using spherical indenters with different diameters.

(a)

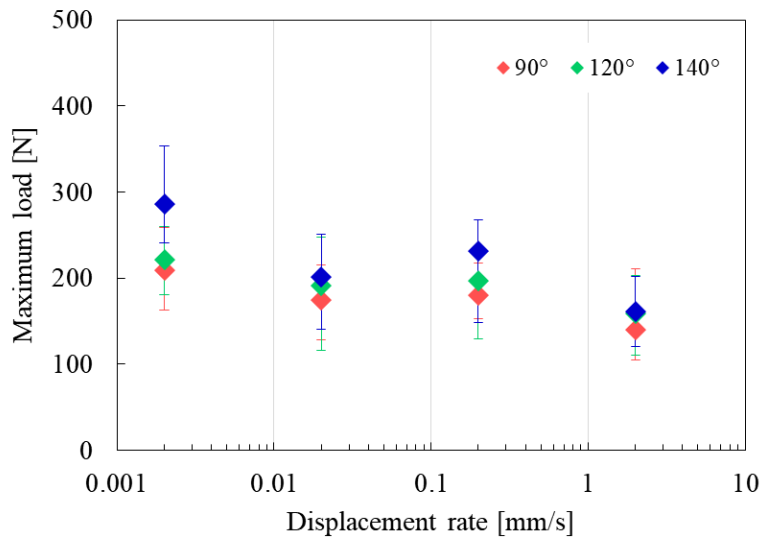

(b)

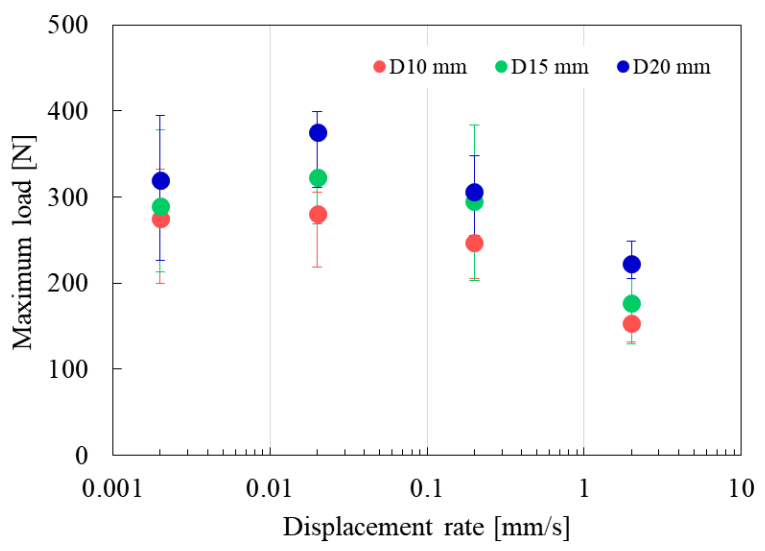

Fig. 6 Relationship between the maximum load and displacement rate when using (a) conical and (b) spherical indenters.

Figure 7 shows the relationship between the displacement at the instant of fracture (hereinafter referred to as the fracture displacement) and the displacement rate. The fracture displacement at $0.002 \mathrm{~mm} / \mathrm{s}$ was larger than that at the other displacement rates, for both conical and spherical indenters. According to the aforementioned load-displacement relationship, in the case of the conical indenters, the fracture occurred with a small displacement at all the displacement rates when the indenter angle was large. In addition, the minimum displacement occurred at the displacement rate of 0.2 $\mathrm{mm} / \mathrm{s}$. This finding indicates that the fracture mode likely changed when the displacement rate increased from 0.02 to $0.2 \mathrm{~mm} / \mathrm{s}$. In contrast, in the case of the spherical indenters, the fracture displacement decreased with an increase in the displacement rate. At small displacement rates, the fracture displacement decreased as the diameter decreased. 
(a)

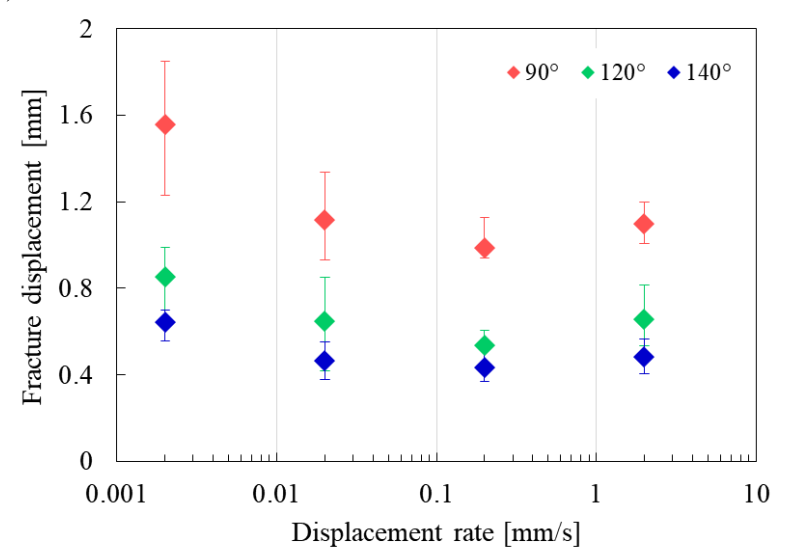

(b)

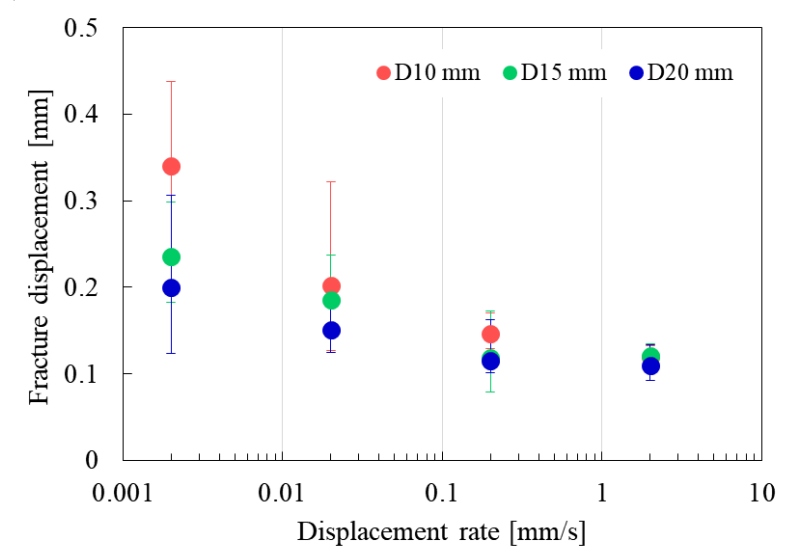

Fig. 7 Relationship between the fracture displacement and displacement rate when using (a) conical and (b) spherical indenters.

Furthermore, the fracture displacements for all the three spherical indenters were nearly equivalent at the displacement rate of $2 \mathrm{~mm} / \mathrm{s}$. These findings imply that a low and high displacement rate correspond to ductile and brittle fracture, respectively, which is qualitatively consistent with the results obtained by conducting a uniaxial test (Schulson, 2001).

\subsection{Visualization of the fracture phase}

Figure 8 shows the process of ice fracturing through conical indenters, obtained using the high-speed camera at a displacement rate of $2 \mathrm{~mm} / \mathrm{s}$. In the case of both the considered indenters, small cracks were generated in the vicinity of the contact point of the indenter. These cracks propagated over time and led to fracture. Owing to the two-dimensional observation, the cracks of the conical indenters did not propagate considerably and were considered to be stagnant in the initial stage of indentation ( 0.10 to $0.30 \mathrm{~s}$ at $90^{\circ}$ (displacement of 0.20 to $0.60 \mathrm{~mm}$ ), 0.10 to $0.18 \mathrm{~s}$ at $140^{\circ}$ (displacement of 0.20 to $0.36 \mathrm{~mm})$ ). The time to fracture for the spherical indenters was smaller than that for the conical indenters, and such stagnation of cracks was not observed when using spherical indenters.

\section{Discussion}

\subsection{Effect of loading method on the ice deformation and fracture 4.1.1 Quasi-static uniaxial compression test}

A quasi-static uniaxial compression test was performed to examine the effect of the loading method. The same testing equipment as that for the quasi-static indentation test was used. A flat indenter (base diameter of $32 \mathrm{~mm}$ ) was attached to the tip of the upper jig. The test conditions, such as the temperature and displacement rate, were the same as those in the indentation test, and the test was performed 7 to 11 times at each displacement rate. The initial strain rates at each displacement rate were $10^{-4}, 10^{-3}, 10^{-2}$, and $10^{-1} \mathrm{~s}^{-1}$.

Figure 9 shows the relationship between the maximum compressive strength and strain rate in the uniaxial compression test. The maximum compressive strength increased from $10^{-4}$ to $10^{-3} \mathrm{~s}^{-1}$ and decreased from $10^{-3}$ to $10^{-1} \mathrm{~s}^{-1}$. This tendency pertaining to the strain rate dependence of the maximum compressive strength is in agreement with the data of previous studies (Jones, 2007). 
(a) $90^{\circ}$

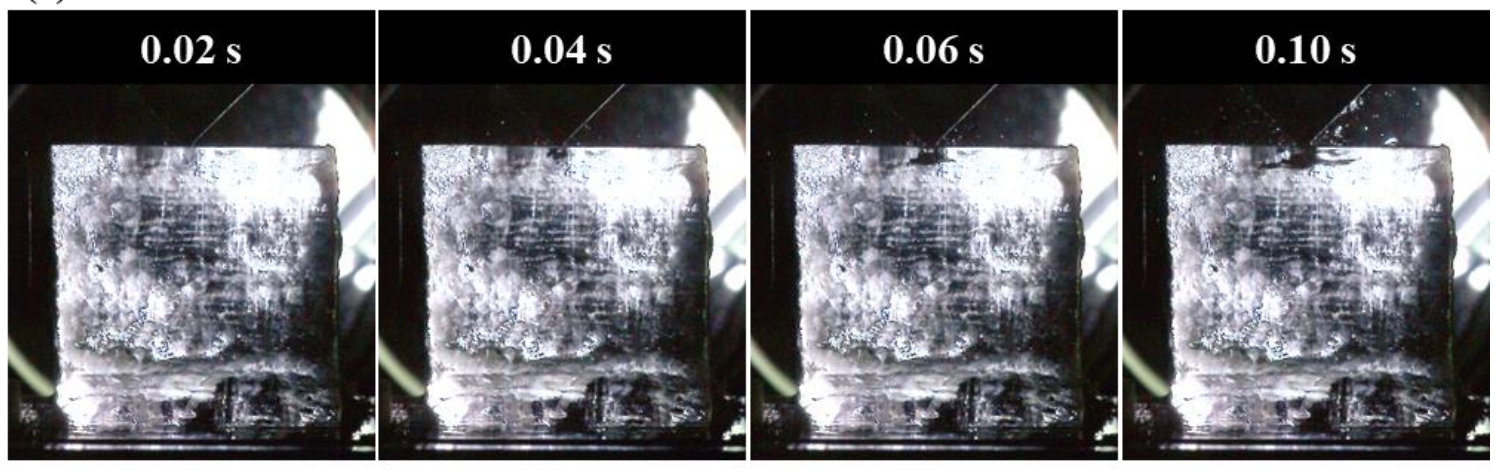
$0.04 \mathrm{~mm}$
$0.08 \mathrm{~mm}$
$0.12 \mathrm{~mm}$
$0.20 \mathrm{~mm}$

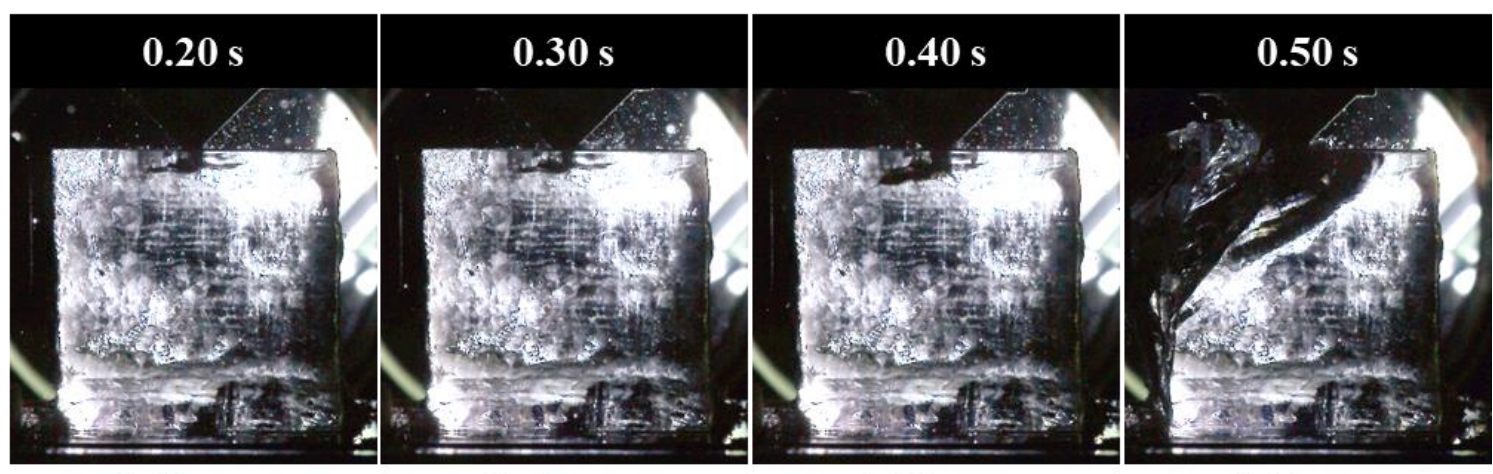
$0.40 \mathrm{~mm}$
$0.60 \mathrm{~mm}$
$0.80 \mathrm{~mm}$
$1.00 \mathrm{~mm}$

(b) $140^{\circ}$

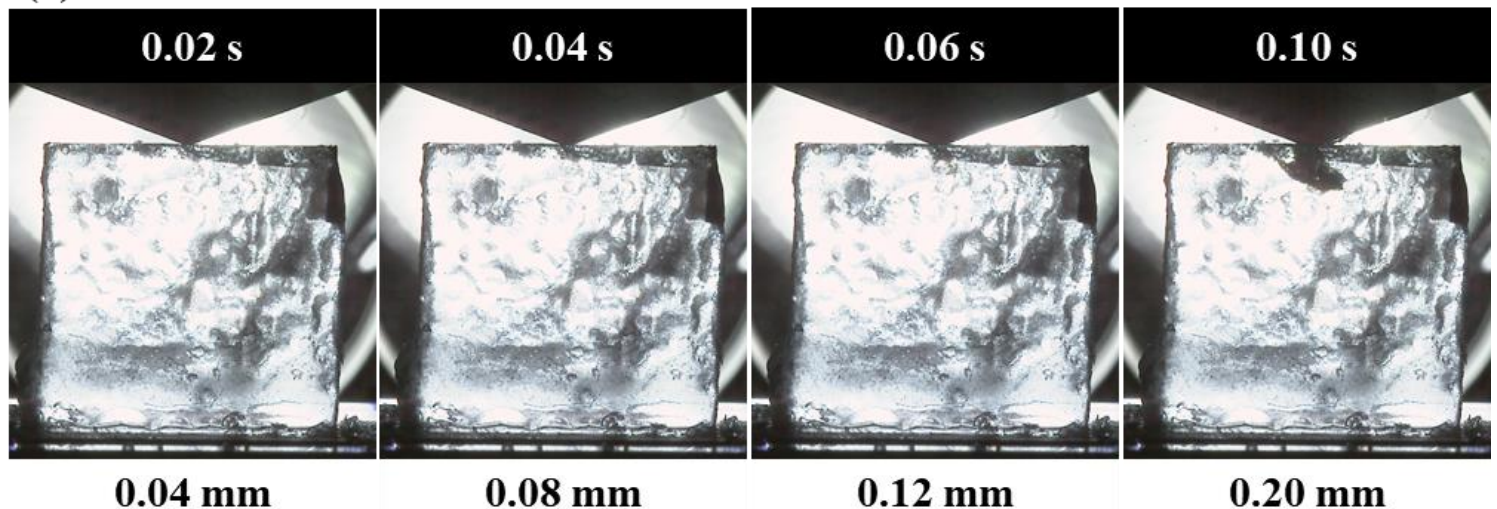

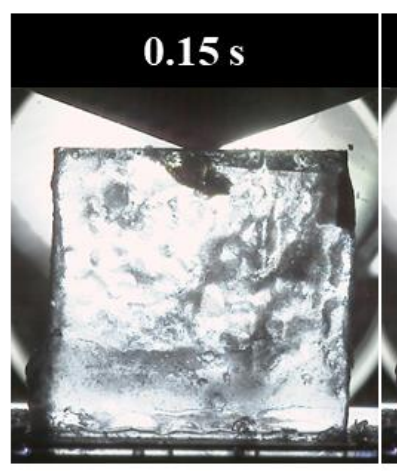

$0.30 \mathrm{~mm}$

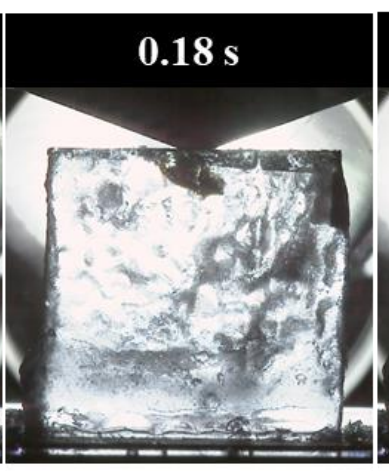

$0.36 \mathrm{~mm}$

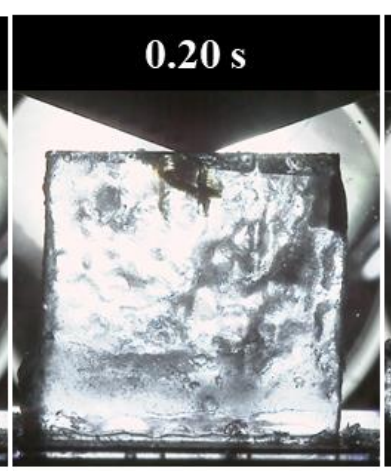

$0.40 \mathrm{~mm}$

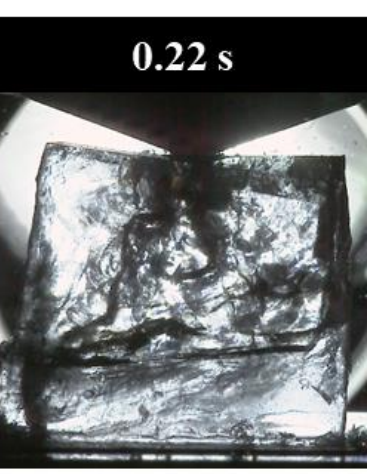

$0.44 \mathrm{~mm}$

Fig. 8 State during indentation performed at a displacement rate $2 \mathrm{~mm} / \mathrm{s}$ by using a conical indenter with indenter angles of (a) $90^{\circ}$ and (b) $140^{\circ}$. The top of each image shows the time since the ice surface and indenter tip came into contact, and the bottom shows the displacement at that time. 


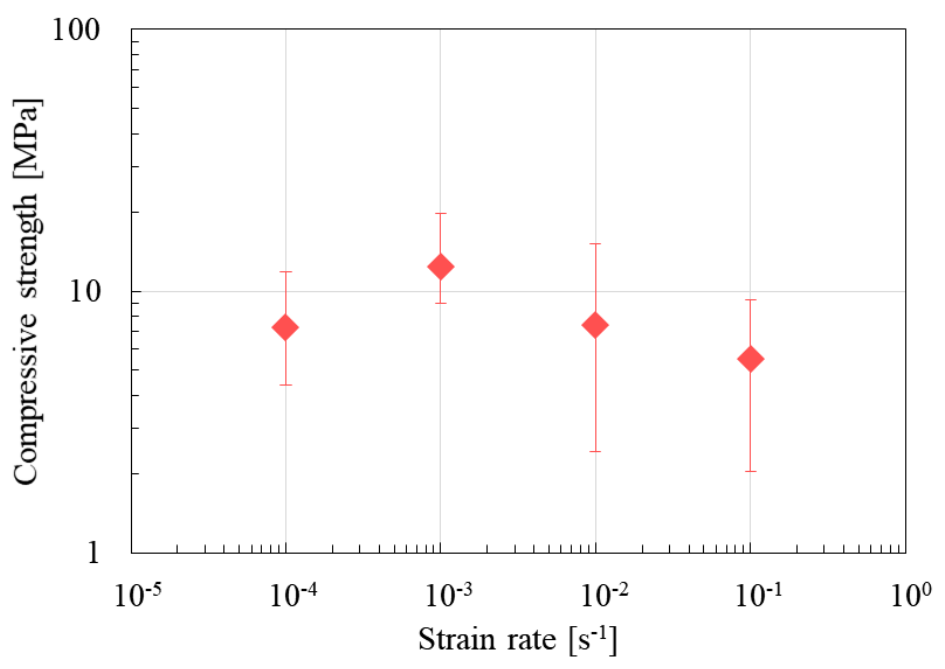

Fig. 9 Relationship between the compressive strength and strain rate in the quasi-static uniaxial compression test.

\subsubsection{Difference between the strain rates in indentation and uniaxial compression tests}

The quasi-static indentation and uniaxial compression tests were compared in terms of the strain rate.

\subsubsection{Conical indenter}

In an indentation test (using a conical indenter) of a metallic material analyzed using the finite element method (FEM), it was observed that the high strain rate region was concentrated near the indenter edge and was present in the annular region extending from the indentation rim (Ogasawara et al., 2015). The relationship between the strain rate $\dot{\varepsilon}$ and distance from the tip of the indenter $Y$ is illustrated schematically in Fig. 10. The strain rate is highest not immediately below the indenter, but at a certain distance. To quantitatively evaluate the strain rate in such an indentation test, the following expression for the effective strain rate has been proposed (Poisl et al., 1994, Lucas and Oliver, 1999).

$$
\dot{\varepsilon_{e}}=\beta\left(\frac{\dot{h}}{h}\right)
$$

where $\dot{\varepsilon}_{e}$ is the effective strain rate, and $\beta$ is the material constant. It is empirically known that the effective strain rate can be related to the uniaxial strain rate. The value of $\beta$ has been studied mainly on creep deformation of metallic materials, and the value of ice has not been clarified. There are many studies in which the deformation mechanism of metallic materials is applied to the deformation of ice (e.g., Glen, 1955; Barnes et al., 1971). Therefore, we use the results of the investigation by Poisl et al. (1994). They reported that $\beta$ ranged from 0.071 to 0.286 . In this study, $\beta$ was assumed to be 0.2 as an average of the reported values. Accurate $\beta$ of ice is an issue for the future.

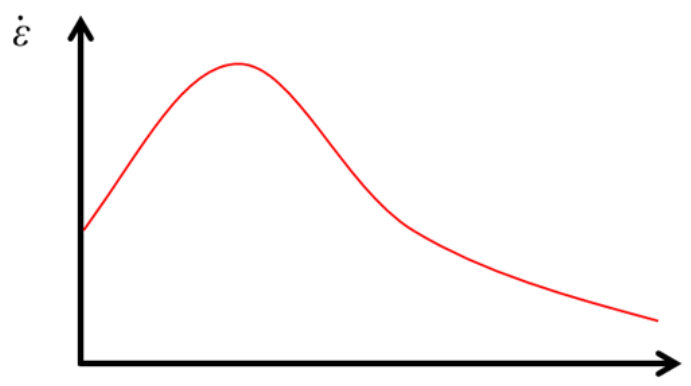

\section{Y}

Fig. 10 Schematic of relationship between the strain rate $(\dot{\varepsilon})$ and depth distance from the tip of the indenter $(Y)$ in an indentation test performed using a conical indenter. 
Figure 11 shows the relationship between the maximum load and effective strain rate in the quasi-static indentation test. There is a difference in the effective strain rate calculated from Eq. (2) even at the same displacement rate because the fracture displacement changes depending on the indenter angle as shown in Fig.7 (a), however this difference is small. The effective strain rate ranged from approximately $10^{-3}$ to $10^{0} \mathrm{~s}^{-1}$. The maximum compressive strength of the ice in this range exhibited a negative rate dependence, and the strength decreased with the increase in the strain rate.

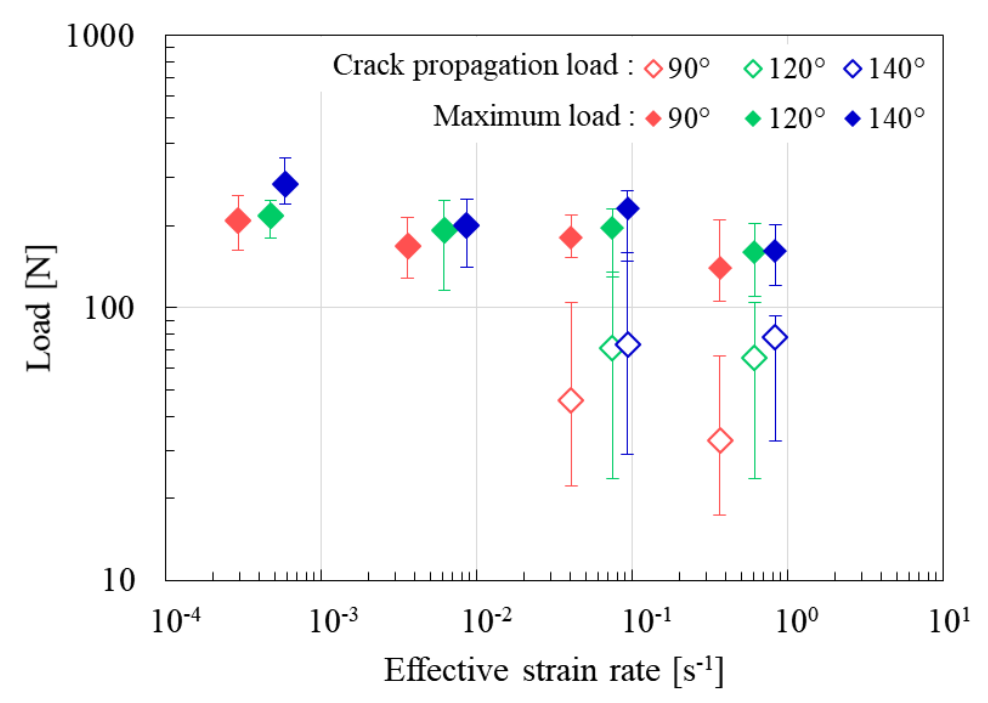

Fig. 11 Relationship between the load (maximum load or crack propagation load) and the effective strain rate when using the conical indenter.

Figure 12 shows the relationship between the strain rate and stress in regions $\mathrm{A}, \mathrm{B}$, and $\mathrm{C}$ under the indenter. As shown in Fig. 10, the strain rate is highest in the B region. As A, B and C corresponded to the region in which the stress exhibits a negative rate dependence (Fig.12 (b)), and the cracks propagated from the high strain rate area of B to the low strain rate area of $\mathrm{C}\left(\dot{\varepsilon}_{\mathrm{B}}>\dot{\varepsilon}_{\mathrm{C}}\right)$, the cracks spread in the direction of increasing stress $\left(\sigma_{\mathrm{B}}<\sigma_{\mathrm{C}}\right)$. It was assumed that the cracks formed immediately after the indentation stagnated owing to the barrier posed by the high stress. The maximum load increased at the strain rates of $10^{-1} \mathrm{~s}^{-1}$ and $10^{0} \mathrm{~s}^{-1}$, likely because the ice was subjected to an additional load after the cracks stagnated. Several load-displacement relationships at the strain rates of $10^{-1} \mathrm{~s}^{-1}$ and $10^{0} \mathrm{~s}^{-1}$ exhibited a decrease in the load before the fracture load was reached, as shown in Figs. 4 (c) and (d), likely because of the crack formation and propagation.

Figure 11 also shows the relationship between the load that initially decreases in the load-displacement relationship (crack propagation load) and the effective strain rate. The crack propagation load tended to decrease almost linearly in the double logarithmic chart, regardless of the indenter angle. This tendency qualitatively agrees with the result of the uniaxial compression test. At strain rates of $10^{-1}$ and $10^{0} \mathrm{~s}^{-1}$, the crack likely did not propagate to the end face of the specimen, as the specimen was considerably large compared to the first generated crack, and hence, the ice did not fracture. This finding suggests that the tendency of the first large crack to grow without stagnation and fracture considerably influences the maximum load.

It should be noted that the effective strain rate considered in this work neglects the change in the strain rate when a crack is formed. In future work, it is necessary to consider the deformation field and strain rate distributions around the ice crack by using simulations such as FEM analyses. 
(a)

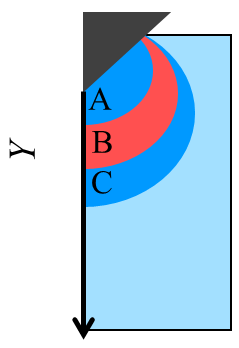

(b)

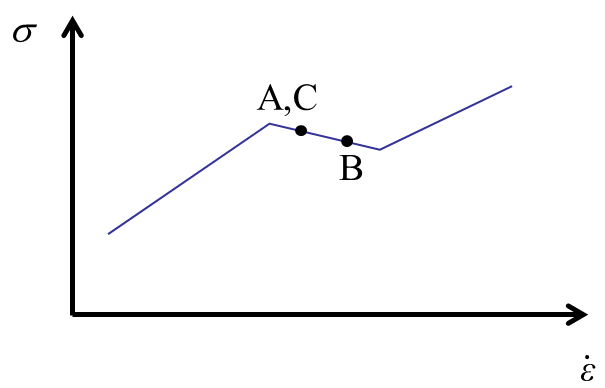

(c)

\begin{tabular}{|c||c|c|c|}
\hline $\begin{array}{c}\text { Distance from the tip of } \\
\text { the indenter }(Y)\end{array}$ & A & B & C \\
\hline \hline Strain rate $(\dot{\varepsilon})$ & Low & High & Low \\
\hline Stress $(\sigma)$ & High & Low & High \\
\hline
\end{tabular}

Fig. 12 (a) Schematic of the strain rate distribution inside ice, (b) relationship between the stress and strain rate in ice,

(c) relationship between the distance from the tip of the indenter, strain rate, and stress indicated in (b).

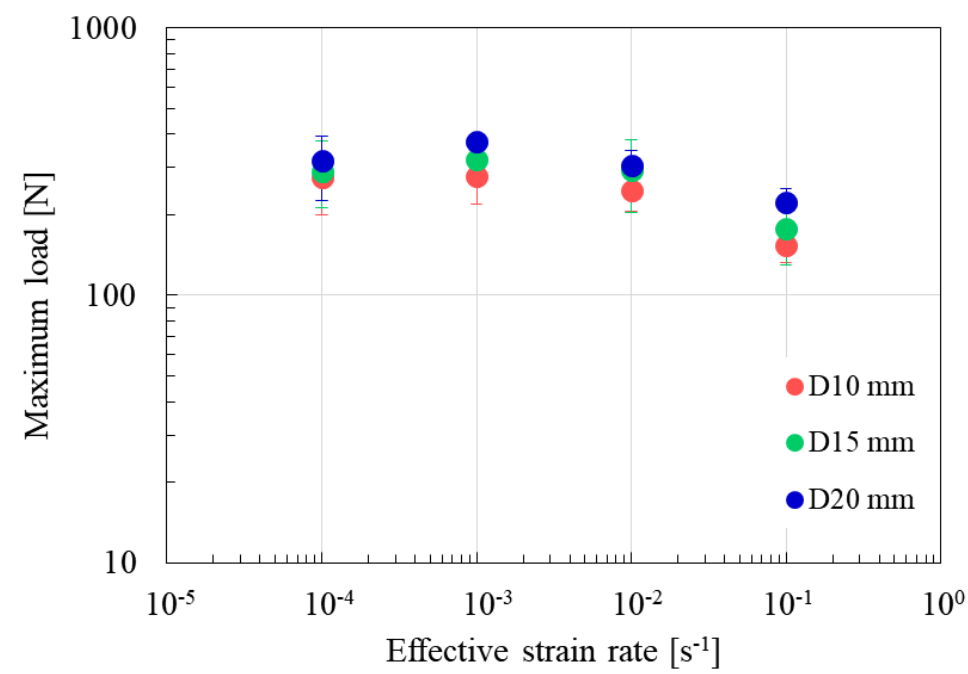

Fig. 13 Relationship between the maximum load and effective strain rate when using spherical indenters.

\subsubsection{Spherical indenter}

To the best of the authors' knowledge, the effective strain rate has not been previously derived, as in the case of conical indenters. Therefore, the effective strain rate of the spherical indenters was considered using the displacement rate and height of the specimen. Figure 13 shows the relationship between the maximum load and effective strain rate when using spherical indenters. The largest maximum load corresponded to the strain rate of $10^{-3} \mathrm{~s}^{-1}$, and it decreased with an increase in the effective strain rate. The tendency of the maximum load at the strain rate ranging from $10^{-4}$ to $10^{-}$ ${ }^{1} \mathrm{~s}^{-1}$ qualitatively agreed with the relationship between the maximum compressive strength and strain rate in the uniaxial compression test, as shown in Fig. 9. As the time to fracture was small in the case of spherical indenters, crack stagnation as in the case of the conical indenters was not observed. However, it is likely that cracks were stagnated in the spherical indenters as well. It was inferred that the fracture occurred in a short time owing to the generation of a wide deformation distribution, as in the uniaxial compression test. Moreover, no crack stagnation was observed using the high-speed camera. 


\subsection{Effect of deformation distribution owing to the indenter shape}

To further consider the deformation and fracture phenomena of ice, the deformation distribution inside the material was examined. Samuels and Mulhearn (1957) examined the strain distribution inside a metallic material indented using spherical and Vickers indenters. The strain distribution in the axial direction inside the material was similar when the contact radius between the indenter and material was the same. Additionally, it has been reported (Ogasawara et al., 2005) that conical and Vickers indenters can be treated as equivalent indenters because the projected area is almost the same when the same displacement is indented. In other words, the results reported by Samuels and Mulhearn (1957) are true for both conical and spherical indenters. Figure 14 schematically illustrates the state when conical and spherical indenters are indented into the material at the same contact radius. The contact radius of the conical $\left(a_{\text {sharp }}\right)$ and spherical indenters ( $\left.a_{\text {spherical }}\right)$ with respect to the displacement ( $h_{\text {sharp }}$ and $h_{\text {spherical }}$, respectively) can be expressed as follows:

$$
\begin{aligned}
& a_{\text {sharp }}=h_{\text {sharp }} \tan \left(\frac{\theta}{2}\right) \\
& a_{\text {spherical }}=\sqrt{h_{\text {spherical }}\left(2 r-h_{\text {spherical }}\right)}
\end{aligned}
$$

where $\theta$ is the indenter apex angle, and $r$ is the indenter radius. In the case of the conical indenters, the shape of the strain distribution does not change even when the displacement increases, because the similarity rule that the ratio of the displacement and contact radius is always constant holds (Fischer-Cripps, 2011). In contrast, this similarity does not exist in the case of the spherical indenters, and the increase rate of the contact radius with respect to the displacement at the initial stage of the indentation is larger than that of the conical indenters.
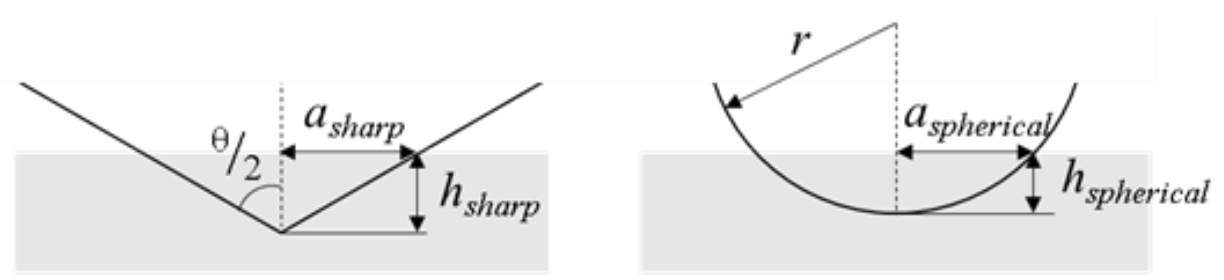

Fig. 14 Schematic of state when conical and spherical indenters are indented into the material at the same contact radius.

Figures 15 (a) and (b) respectively show the relationship of the fracture displacement and contact radius at the time of fracture (hereinafter referred to as the fracture contact radius) with the indenter angle. Figures 16 (a) and (b) show the relationship of the fracture displacement and fracture contact radius with the sphere diameter, respectively. As mentioned previously, the fracture displacement decreased as the indenter angle or diameter increased. Furthermore, the spherical indenters could fracture the ice specimen with less displacement than that in the case of the conical indenters. In contrast, the fracture contact radius at the same displacement rate did not change considerably for different indenter shapes. This finding implies that the fracture occurred when an equivalent deformation distribution was formed in the axial direction.

The contact radius tended to decrease as the displacement rate increased; however, the radius increased slightly at the rate of $2 \mathrm{~mm} / \mathrm{s}$ when using conical indenters. To further examine the fracture near the surface of the ice specimen during the indentation, Figure 17 shows still images during the indentation of a $90^{\circ}$ conical indenter at each displacement rate. At a low displacement rate, no change was observed around the indenter. However, at a high displacement rate, small ice fragments were generated from the surface near the indenter edge, indicating brittle fracture. The generation of this fragment occurred intermittently. It is considered that the internal deformation distribution became smaller owing to the surface fracture, and the contact radius increased as the ice had to be indented further to induce fracturing.

\section{Conclusion}

In this study, the effects of the indenter shape and loading method on ductile and brittle behavior during deformation and fracture for pure ice were discussed from the viewpoint of the displacement rates and effective strain rates by conducting a quasi-static indentation test. The following conclusions could be derived. 
(a)

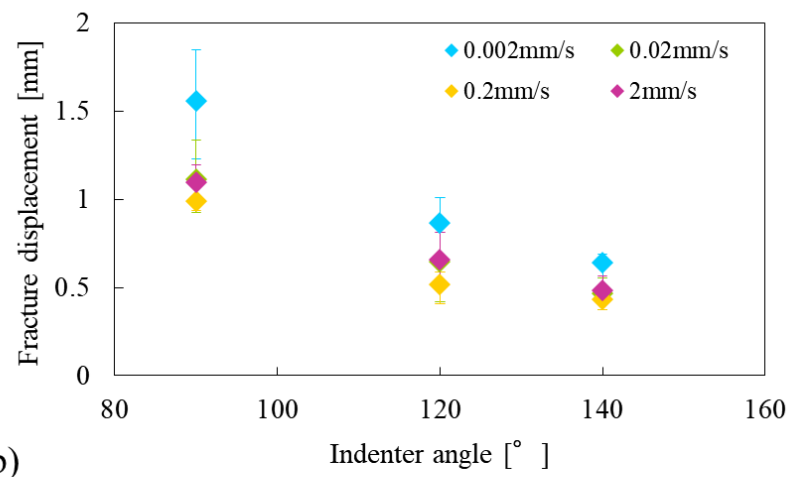

(b)

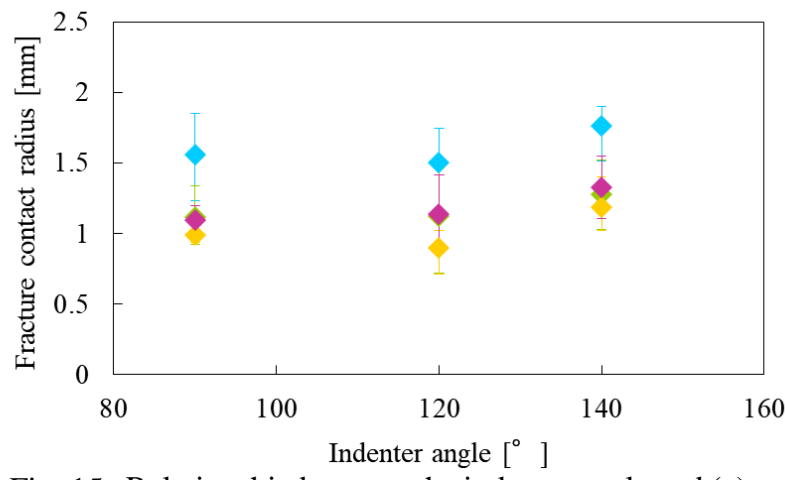

Fig. 15 Relationship between the indenter angle and (a) fracture displacement (b) fracture contact radius when using conical indenters. (a)
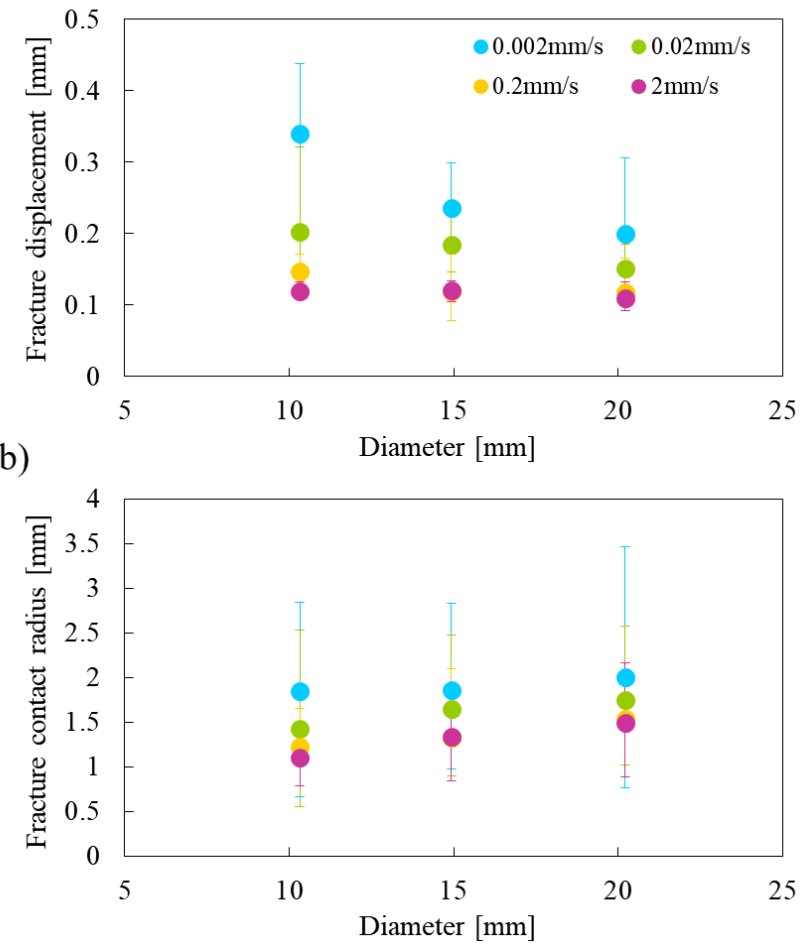

Fig. 16 Relationship between the sphere diameter and (a) fracture displacement (b) fracture contact radius when using spherical indenters.
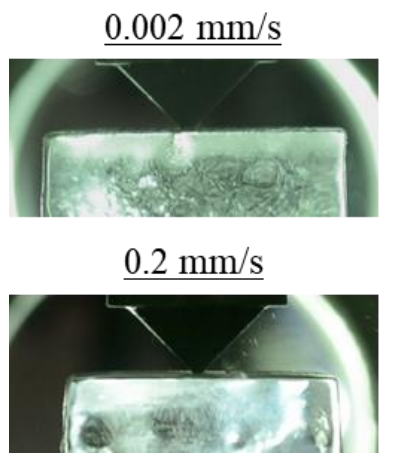

Fig. 17 State during indentation of the $90^{\circ}$ conical indenter.

The results of the indentation test were compared with those of a uniaxial compression test to evaluate the effect of the loading method. The displacement rates of the conical indenter were transformed into the effective strain rates to enable the comparison. The maximum load increased at the effective strain rates of $10^{-1}$ and $10^{0} \mathrm{~s}^{-1}$. This result could be attributed to the crack stagnation caused by the negative rate dependence of the ice strength. In contrast, the result of the spherical indenters was compared with that of the uniaxial compression test, when the effective strain rate was considered in terms of the displacement rate and specimen height. The maximum load at effective strain rates ranging from $10^{-4}$ to $10^{-1} \mathrm{~s}^{-1}$ indicated a similar trend to that observed in the uniaxial compression test; specifically, the maximum load was the largest at $10^{-3} \mathrm{~s}^{-1}$ and decreased with an increase in the effective strain rates. This finding indicates that a wide deformation distribution similar to that in the uniaxial compression test was generated owing to the large contact area of the spherical indenter.

In the indentation test, the axial strain distribution inside the material was similar under similar contact radii. The contact radius when the ice fractured did not change considerably for different indenter shapes. It was considered that the deformation distribution inside the ice, induced by the indentation, considerably influenced the deformation and fracture of the ice. As the indenter angle of the conical indenter or diameter of the spherical indenter increased, the 
deformation distribution inside the ice became larger, and the fracture occurred at a smaller displacement. Similarly, the spherical indenter could fracture the ice at a smaller displacement owing to its larger contact area and the formation of a wider range of deformation distribution compared to those in the case of a conical indenter.

Thus, it was experimentally demonstrated that the internal deformation distribution considerably influences the deformation and fracture properties of ice. Nevertheless, certain aspects must be further examined in future work. In particular, the deformation distribution and strain rate distribution adopted in this work do not take into account the changes caused by crack initiation and propagation. This aspect should be investigated using simulations such as FEM analyses. Moreover, the initiation and propagation behavior of the cracks in three dimensions was not clarified in this work. In this regard, it is necessary to adopt methods such as performing stereo image processing on images recorded in two directions or introducing fracture mechanics. Furthermore, we examined specimens with only one size, and future work should attempt to examine the effect of the size of the specimen on the indentation testing.

\section{Acknowledgement}

This study was supported by JSPS KAKENHI Grant Number JP17H03152. The authors would like to thank Dr. Yoshikazu Teraoka for teaching us how to observe the polarization photographs of ice crystals.

\section{References}

Ahmad, S. and Whitworth, R.W., Dislocation motion in ice: a study by synchrotron X-ray topography, Philosophical Magazine A, Vol.57, No.5 (1988), pp.749-766.

Arakawa, M., Shirai, K. and Kato, M., Shock wave and fracture propagation in water ice by high velocity impact, Geophysical Research Letters, Vol.27, No.3 (2000), pp.305-308.

Barnes, P., Tabor, D. and Walker, J. C. F., The friction and creep of polycrystalline ice, Proceedings of the Royal Society A, Vol.324 (1971), pp.127-155.

Barrette, P., Pond, J. and Jordaan, I. J., Ice damage and layer formation: in small-scale indentation experiments, Ice in the Environment: Proceedings of the 16th International Association for Hydraulic Engineering and Research (IAHR) International Symposium on Ice (2002), pp.246-253.

Clark, P. U., Alley, R. B. and Pollard, D., Northern hemisphere ice-sheet influences on global climate change, Science, Vol. 286 (1999), pp.1104-1111.

Cole, D. M., Strain-rate and grain-size effects in ice, Journal of Glaciology, Vol.33, No.115 (1987), pp.274-280.

Fischer-Cripps, A. C., Nanoindentation, Third edition (2011), Springer.

Glen, J. W., The creep of polycrystalline ice, Proceedings of the Royal Society of London A, Vol.228 (1955), pp.519538.

Gold, L. W., Engineering properties of fresh-water ice, Journal of Glaciology, Vol.19, No.81 (1977), pp.197-212.

Hawkes, I. and Mellor, M., Deformation and fracture of ice under uniaxial stress, Journal of Glaciology, Vol.11, No.61 (1972), pp.103-131.

Higashi, A., Koinuma, S. and Mae, S., Plastic yielding in ice single crystals, Japanese Journal of Applied Physics, Vol.3, No.10 (1964), pp.610-616.

Hoge, K. G. and Mukherjee, A. K., The temperature and strain rate dependence of the flow stress of tantalum, Journal of Materials Science, Vol.12 (1977), pp.1666-1672.

Jones, S. J., A review of the strength of iceberg and other freshwater ice and the effect temperature, Cold Regions Science and Technology, Vol.47 (2007), pp.256-262.

Kawakami, S., Mizutani, H., Takagi, Y., Kati, M. and Kumazawa, M., Impact experiments on ice, Journal of Geophysical Research, Vol.88 (1983), pp.5806-5814.

Kim, H. and Keune, J. N., Compressive strength of ice at impact strain rates, Journal of Materials Science, Vol.42 (2007), pp.2802-2806.

Lucas, B. N. and Oliver, W. C., Indentation power-law creep of high-purity indium, Metallurgical and Materials Transactions A, Vol.30A (1999), pp.601-610.

Mackey, T., Wells, J., Jordaan, I. J. and Derradji-Aouat, A., Experiments on the fracture of polycrystalline ice, Proceedings of the 19th International Conference on Port and Ocean Engineering under Arctic Conditions (POAC 
'07) (2007), pp.339-349.

Mellor, M. and Cole, D. M., Deformation and failure of ice under constant stress or constant strain-rate, Cold Regions Science and Technology, Vol.5, No.3 (1982), pp.201-219.

Michel, B. and Toussaint, N., Mechanisms and theory of indentation of ice plates, Journal of Glaciology, Vol.19, No.81 (1977), pp.285-300.

Murata, K., Asakawa, H., Nagashima, K., Furukawa, Y. and Sazaki, G., Thermodynamic origin of surface melting on ice crystals, Proceedings of the National Academy of Sciences of the United States of America, Vol.113, No.44 (2016), E6741-6748.

Ogasawara, N., Chiba, N. and Chen X., Representative strain of indentation analysis, Journal of Materials Research, Vol.20, No.8 (2005), pp.2225-2234.

Ogasawara, N., Shimizu, Y., Kami, T. and Yamada, H., Influence of strain rate on strain field for sharp indentation, Journal of the Society of Materials Science, Japan, Vol.64, No.10 (2015), pp.783-789.

Oliver, W. C., An improved technique for determining hardness and elastic modulus using load and displacement sensing indentation experiments, Journal of Materials Research, Vol.7, No.6 (1992), pp.1564-1583.

Peterson, H., Bailey, M. and Hallet, J., Ice particle growth under conditions of the upper troposphere, Atmospheric Research, Vol.97, No.4 (2010), pp.446-449.

Poisl, W. H., Oliver, W. C. and Fabes, B. D., The relationship between indentation and uniaxial creep in amorphous selenium, Journal of Materials Research, Vol.10, No.8 (1994), pp.2024-2032.

Ros, K. and Johansen, A., Ice condensation as a planet formation mechanism, Astronomy and Astrophysics, Vol.552 (2013), A137.

Samuels, L. E. and Mulhearn, T. O., An experimental investigation of the deformed zone associated with indentation hardness impressions, Journal of the Mechanics and Physics of Solids, Vol.5 (1957), pp.125-134.

Schulson, E. M., The brittle compressive fracture of ice, Acta Metallurgica et Materialia, Vol.38, No.10 (1990), pp.19631976.

Schulson, E. M., The brittle failure of ice under compression, The Journal of Physical Chemistry B, Vol.101, No.32 (1997), pp.6254-6258.

Schulson, E. M., Brittle failure of ice, Engineering Fracture Mechanics, Vol.68 (2001), pp.1839-1887.

Schwartz, J. and Weeks, W. F., Engineering properties of sea ice, Journal of Glaciology, Vol.19, No.81 (1977), pp.199531.

Smoluchowski, R., Formation of $\mathrm{H} 2$ on amorphous ice grains and their importance for planetary atmospheres, Astrophysics and Space Science, Vol.65 (1979), pp.29-38.

Timco, G. W. and Weeks, W. F., A review of the engineering properties of sea ice, Cold Regions Science and Technology, Vol.60, No.2 (2010), pp.107-129.

Tsuda, T., Hayashi, H., Yamamoto, T., Abe, A. and Tanimura, S., Dynamic tensile properties of engineering plastics over a wide range of strain rates, Journal of Solid Mechanics and Materials Engineering, Vol.6, No.6 (2012), pp.711720 .

Ulan-Kvitberg, C., Kim, H. and Daley, C., Comparison of pressure-area effects for various ice and steel indenters, Proceedings of the 2011 International Offshore and Polar Engineering Conference (2011), pp.1048-1055.

Wei, X., Miranda, P. B. and Shen, Y. R., Surface vibrational spectroscopic study of surface melting of ice, Physical Review Letters, Vol.86 (2001), pp.1554-1557.

Wells, J., Jordaan, I. J., Derradji-Aouat, A. and Taylor, R., Small-scale laboratory experiments on the indentation failure of polycrystalline ice in compression: Main results and pressure distribution, Cold Regions Science and Technology, Vol.65 (2011), pp.314-325.

Wu, X. and Prakash, V., Dynamic strength of distill water and lake water ice at high strain rates, International Journal of Impact Engineering, Vol.76 (2015), pp.155-165.

Yokoyama, E., Yoshizaki, I., Shimaoka, T., Sone, T., Kiyota, T. and Furukawa, Y., Measurements of growth rates of an ice crystal from supercooled heavy water under microgravity conditions - Basal face growth rate and tip velocity of a dendrite, Journal of Physical Chemistry B, Vol.115, No.27 (2011), pp.8739-8745.

Yokoyama, Y., East, T. M., Thompson, W. G., Thomas, A. L., Webster, J. M., Miyairi, Y., Sawada, C., Aze, T., Matsuzaki, H., Okuno, J., Fallon, S., Braga, J., Humblet, M., Iryu, Y., Potts, D. C., Fujita, K., Suzuki, A. and Kan, H., Rapid glaciation and a two-step sea level plunge into the last glacial maximum, Nature, Vol.559 (2018), pp.603-607. 